\title{
Constriction band sequence along with associated malformations
}

\author{
Sadia Effendi ${ }^{1}$, Pushpa Goswami ${ }^{2}$, Mahesh Kumar ${ }^{3}$ \\ ${ }^{1}$ Resident (FCPS) Department of plastic surgery Liaquat University Hospital Jamshoro Sindh Pakistan \\ ${ }^{2}$ Assistant professor of Anatomy Liaquat University of Medical and Health Sciences Jamshoro Sindh Pakistan \\ ${ }^{3}$ Associate Professor of Department of plastic surgery Liaquat University Hospital Jamshoro Sindh Pakistan
}

\begin{abstract}
Amniotic Band Sequence (ABS) also known as Amniotic Deformity, adhesion, and Mutilation (ADAM) complex or Congenital Constriction Band Syndrome (CCBS) had variety of presentation and is cause of disfigurement and disability in the newborn. This retrospective study was conducted in department of Plastic and Reconstructive Surgery, Liaquat University Hospital Jamshoro, Sindh Pakistan to determine presentation of constriction band syndrome and its association with other congenital anomalies seen at our institution.

Ten patients with constriction band syndrome were included in the study. All were admitted through the outpatient department. The site and extent of each constricting ring and related anomalies were recorded. Surgery was performed. The most common associated anomalies were syndactyly, acrosyndactyly, hypo plastic phalanges, lymph edema and Talipes Equino Varus. Such type of study in our population is conducted for the first time which shows that constriction band syndrome is also not uncommon in our setup and successful surgical repair is also possible. Further research is also required in order to diagnose this in uterus, intra uterine lysis/ surgical intervention and possible causative factors needs elaboration.
\end{abstract}

Key words: amputation, constriction band syndrome, hypo plastic fingers, lymph edema, radial nerve palsy

\section{Introduction}

Congenital Constriction Band Syndrome (CCBS) is an uncommon, congenital fetal abnormality with multiple disfiguring and disabling manifestations occurring in approximately 1 in 1200 to 1 in 15000 live births. Clinical manifestations of CCBS are extremely variable and their extent may range from a single abnormality, like a constriction ring, to multiple abnormalities. Portal in 1685 report the first case inspite of recognition for more than 300 years still satisfactory mechanism of pathogenesis is unknown. Fetal anomalies in CCBS are caused by a variety of mechanisms including aberrant embryonic morphogenesis, fetal/embryonic vascular compromise, mechanical deformations and secondary disruption of normally developed structures. $[1,2,3]$ A critical analysis of these cases calls for reevaluation of pathogenesis of the following three cited theories.

Intrinsic theory is proposed by Streeter in 1930 he suggest that germ defect is in the embryonic disc as well as the amniotic cavity. Streeter thought that bands represented macerated sheets of epidermis and the residual of defective local tissue. The presence of systemic and internal visceral anomalies could only be explained by this theory. [4]

Extrinsic theory which is widely accepted was proposed by Torpin and Faulkner in 1965 hypothesizes separation of amnion from the choroin during early pregnancy which produces free-floating tissue bands which either wrap around parts of the embryo in a band-like manner or are swallowed by the fetus. The bands restrict growth or cause structural defects in the fetus. The fetus' limbs, while trapped there are subjected to vascular compression and then necrosis. Early rupture would lead to more severe malformations (e.g., craniofacial and visceral) whereas later rupture would lead to milder forms. Oligohydramnios may worsen the deformity through compression [5]

Intrauterine trauma theory postulated by Kino believes that congenital constrictions, amputations and acrosyndactyly are caused by intrauterine trauma during pregnancy which disrupts blood supply or result from simple mechanical disruption or deformation, caused directly by fibrous bands or streaks that entangle the developing fetal parts. Today, most agree that there is no genetic predisposition to this condition. [6]

Aim of this study was to ascertain presentation of constriction band syndrome in our center and its association with other congenital anomalies.

\section{Materials and methods}

This retrospective study was conducted in the department of Plastic and Reconstructive Surgery Liaquat University Hospital Jamshoro, Sindh Pakistan from January 2010 to December 2012. Patients presenting with the features of the constriction band syndrome were included in the study. A total of 10 patients admitted through the outpatient department. After consent detailed history was taken and complete physical examination was performed which specifically noted constrictions of the extremities including digits and accompanying anomalies. The site and extent of each ring was recorded and they were classified into four types 
according to Patterson criteria. Surgical procedures performed included excision of constriction rings followed by Z-plasty. Patients with acrosyndactyly/syndactyly had their fingers or toes separated; the site of tissue loss was either closed by local flaps or graft. Time and type of surgery are important to provide the best functional and aesthetic results. Most of these procedures were staged with an average interval of 3 to 6 months. $[7,8,9]$

\section{Observations}

Out of 10 patients, 5 were males (50\%) and 5 were females (50\%). Age range was 10 months-20 years. The pattern of limb involvement in this study shows upper limbs involvement 01 patient on the right side, 03 patients on the left side, 01 patient had both arms involved and in 01 patient both right arm and right leg was involved. Lower limb involvement was seen in 01 patient on right side, 02 patients on left side and 01 patient had both lower limbs involved.

Table 1 showing age, sex and site of limb involvement with associated anomalies

\begin{tabular}{|c|c|c|c|}
\hline $\begin{array}{l}\text { Case } \\
\#\end{array}$ & $\begin{array}{ll}\text { Age } & \text { of } \\
\text { Patient } & \end{array}$ & $\begin{array}{l}\text { Sex of } \\
\text { patient }\end{array}$ & Site of constriction band and associated anomalies \\
\hline 1 & 3years & Male & $\begin{array}{l}\text { Constriction ring in both legs with lymph edema in right foot and left club } \\
\text { foot.(Fig 1) }\end{array}$ \\
\hline 2 & 1year & Female & Contracture of left lower thigh above knee with hypo plastic toe fingers. (Fig 2) \\
\hline 3 & 2 year & Male & $\begin{array}{l}\text { Amputed fingers of both hands, in right hand middle and ring and in left hand } \\
\text { index, middle, and ring. (Fig 3). }\end{array}$ \\
\hline 4 & 07 months & Female & constriction band of index and little finger along with acrosyndactyly.(fig 4) \\
\hline 5 & $\begin{array}{l}\text { 01year and } \\
06 \text { months }\end{array}$ & Female & $\begin{array}{l}\text { constriction band syndrome of right arm with type three constrictions associated } \\
\text { with radial nerve palsy along with ischemic ulcers on the dorsum of hand along } \\
\text { with right club foot.(fig } 5,6,7 \text { ) }\end{array}$ \\
\hline 6 & 04 years & Female & Constriction band of right lower arm with lymph edema of forearm. (Fig 8) \\
\hline 7 & 20 years & Female & $\begin{array}{l}\text { constriction band of middle finger with amputed index finger, and hypoplastic } \\
\text { ring and little finger.(fig 9) }\end{array}$ \\
\hline 8 & O8 months & Male & right lower leg constriction band syndrome with hypoplatic toe fingers.(fig 10) \\
\hline 9 & 01 year & Male & $\begin{array}{l}\text { Constriction band of left upper leg with left club foot and associated cleft lip } \\
\text { deformity. (Fig 11) }\end{array}$ \\
\hline 10 & 04months & Male & $\begin{array}{l}\text { Constriction bands involving middle finger with massive swelling distal to deep } \\
\text { constriction syndrome along with syndactyly. (Fig 12) }\end{array}$ \\
\hline
\end{tabular}

Table 2 showing associated anomalies of hands in constriction band syndrome.

\begin{tabular}{|l|l|l|}
\hline Hand anomalies & Right side & Left side \\
\hline Syndactyly & 0 & 1 \\
\hline Acroyndactyly & 0 & 1 \\
\hline Hypoplastic phalanges & 0 & 1 \\
\hline Amputed fingers & 2 & 1 \\
\hline Lymphedema & 1 & 0 \\
\hline
\end{tabular}

Table 3 showing associated anomalies of foot in constriction band syndrome.

\begin{tabular}{|l|l|l|}
\hline Foot anomalies & Right side & Left side \\
\hline Syndactyly & 0 & 1 \\
\hline Acroyndactyly & 0 & 0 \\
\hline Hypoplastic toe fingers & 1 & 0 \\
\hline Talipes equinovarus (club foot) & 1 & 2 \\
\hline Lymphedema & 1 & 1 \\
\hline
\end{tabular}




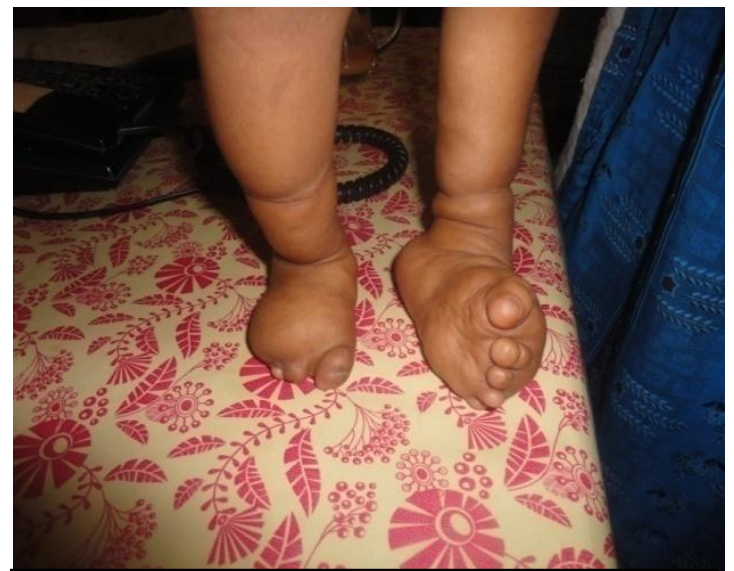

Fig1. Constriction bands involving lower limbs along with Ivmph edema and club

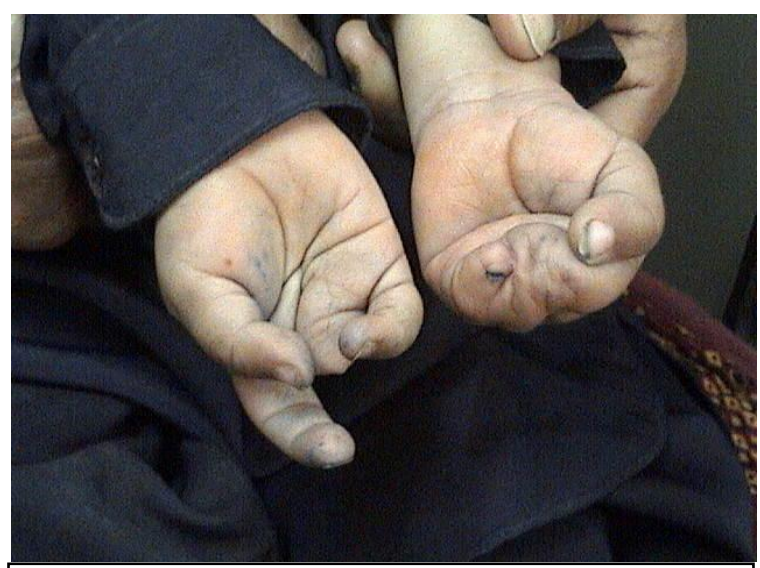

Fig3. Constriction bands with amputed digits

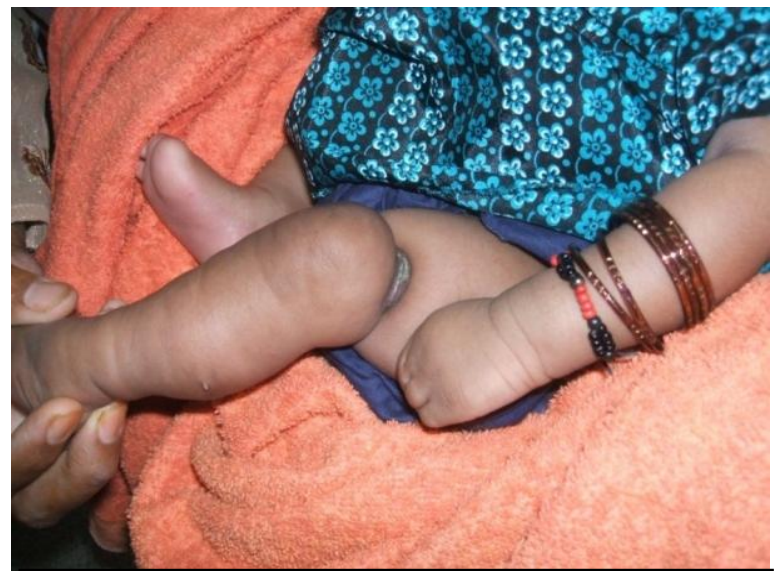

Fig2.Constriction bands involving left thigh above knee

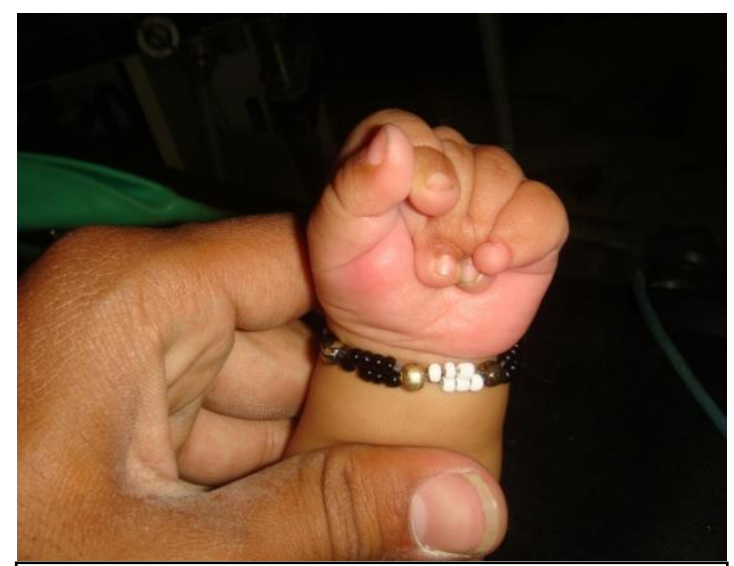

Fig4.Constriction bands involving left index and little fingers with associated

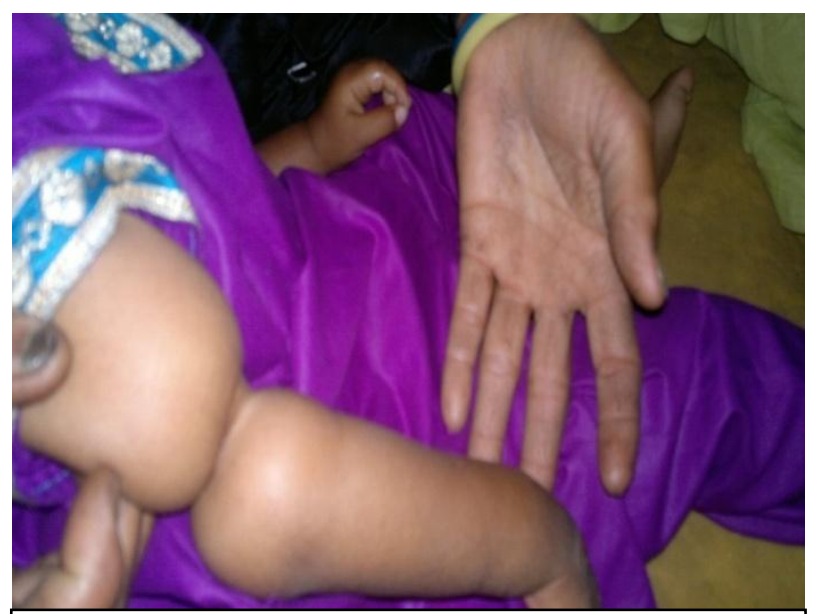

Fig5. Constriction bands involving right arm above elbow

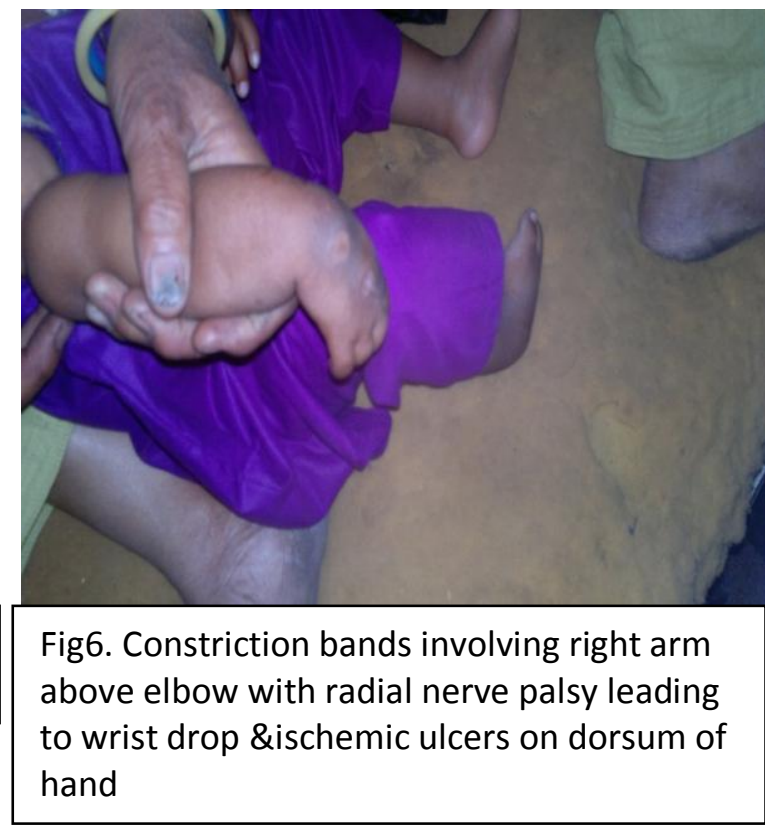




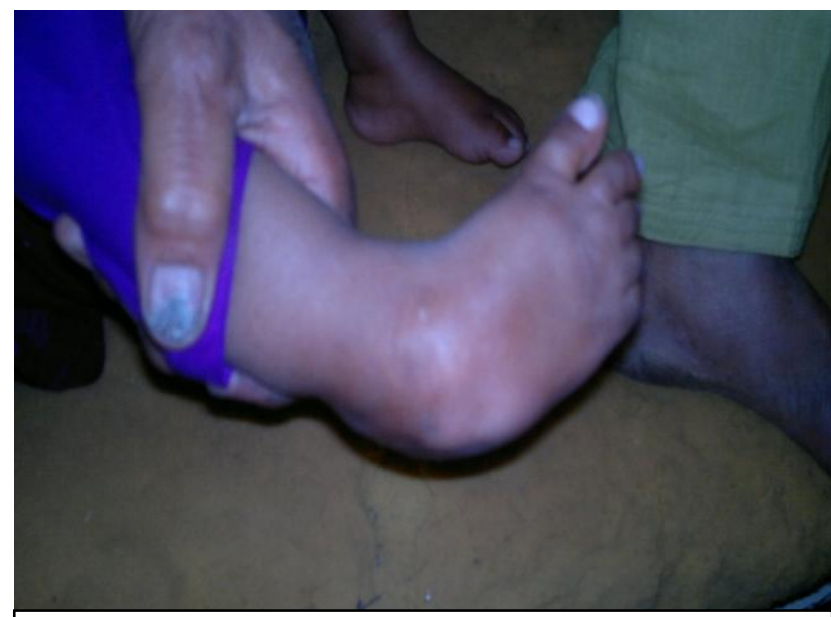

Fig7. Constriction bands involving right arm above elbow with right club foot

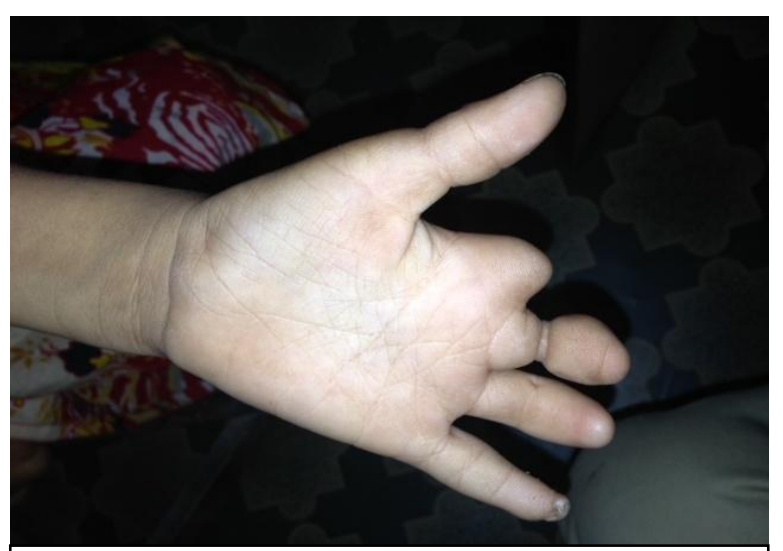

Fig9. Constriction bands involving middle finger, amputed index finger, hypoplastic ring and little finger

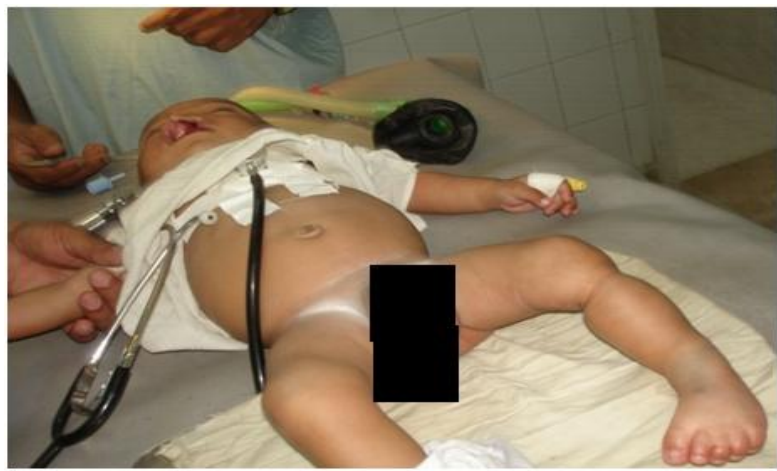

Fig11. Constriction bands involving left leg with club foot and cleft lip deformitv

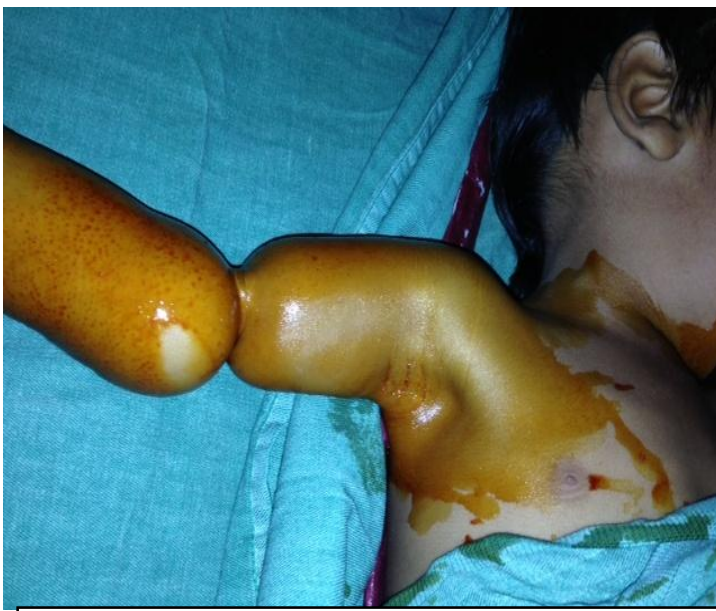

Fig8. Constriction bands involving right arm above elbow with lymph oedema

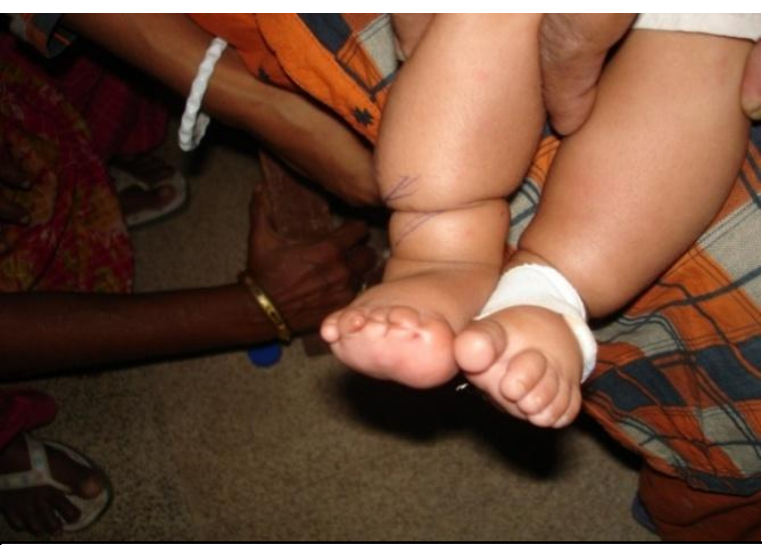

Fig10. Constriction bands involving right lower leg with hypoplastic fingers.

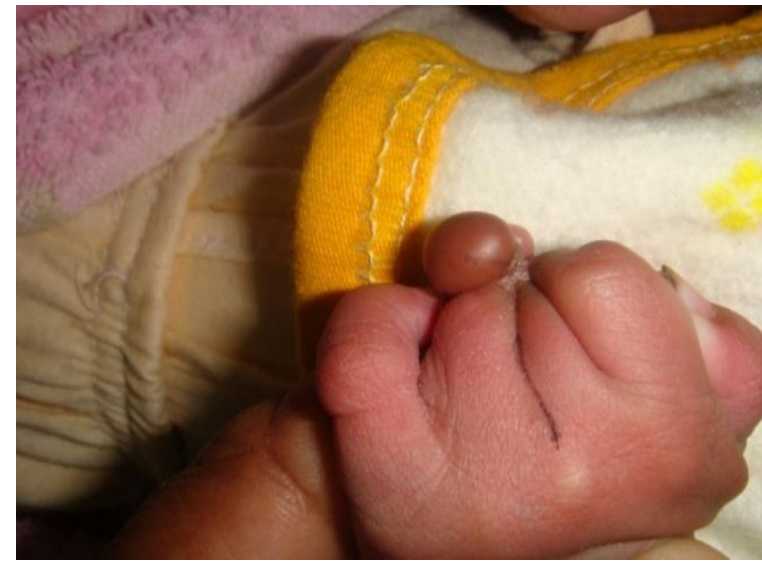

Fig12. Constriction bands left middle finger with massive swelling distal to deep constriction along with syndactyly 


\section{Discussions}

Amniotic bands, also called constriction bands, congenital rings, Streeter dysplasia and annular defects are anomalous bands that encircle either partially or completely, a digit or an extremity.

Amniotic Band Sequence (ABS) is a rare disruptive condition, with a variable spectrum of congenital defects caused by fibrous bands emerging as a result of amniotic rupture in the first trimester of gestation. Early rupture would lead to more severe malformations (e.g. craniofacial and visceral) whereas later rupture would lead to milder forms. Several factors, such as young parental age, primigravidity, febrile maternal illness, and drug use in the first trimester, were postulated to have substantial influence on ABS prevalence rate. Familial occurrence is very rare as seen in only one patient in our study and there is no known genetic predisposition. It is usually accepted that fibrous bands appear due to rupture of amnion in early pregnancy and its attachment on the fetal body, leading to constrictions, amputation and post natal deformities secondary to immobilization. The numbers of associated anomalies in our study were lower than in other studies. [10,11, 12]

According to Patterson's diagnostic criteria for ABS, there should be presence of at least one of the following: 1) simple ring constrictions seen in case no.2 Table 1 (fig 2)

2 ) ring constrictions with distal deformity with or without lymph oedema, lymph oedema seen in case no. 01 Table 1 (fig 1) case no. 06 Table 1 (fig 8)

3) Ring constrictions accompanied by syndactyly or acrosyndactyly, seen in case no.4 Table 1 (fig4) and in case no.10 Table 1 (fig 12)

4) Amputation seen in case no. 3 Table 1 and figure 3.

From previous studies the most frequent organs involved in ABS are the fingers and toes with or without association with cleft lip and palate this study also shows fingers and toes frequently involved shown in Table 2 and Table 3 with cleft lip in one case. $[13,14]$

Musculoskeletal disorders commonly associated with ABS include club foot seen in three cases (fig 1, 7,11), syndactyly (as seen in the fig.12) or acrosyndactyly seen in case no.4 (fig 4), hypoplastic fingers seen in case no 07 and 08 (fig 9,10), peripheral nerve defects seen in one patient ( radial nerve palsy with wrist drop in case no.5 figure 6), distal lymph oedema in case no. 01 Table 1 (fig 1) case no. 06 Table 1 (fig 8), intra-uterine amputations in one case only involving fingers seen in case no.3 Table 1 and figure 3, cleft lip seen in case no. 09 Table 1 fig 11 while pseudoarthrosis of underlying bones ,cleft palate and umbilical hernias are not seen in our study.[15]

Prenatal diagnosis by means of ultrasonography, fetal magnetic resonance imaging and fetoscopy is possible. On obstetric ultra sound scan, amniotic bands can be seen as linear echoes floating in the amniotic fluid and connected to the fetal body such abnormalities are generally diagnosed at the end of the first or the beginning of the second trimester using two-dimensional ultrasonography (2DUS). Three-dimensional ultrasonography (3DUS) in rendering mode allows spatial analysis of the fetus and amniotic band, thus enabling better comprehension of this pathological condition and better counseling for the parents $[16,17,18,19]$

Mild simple constrictions may not require any treatment, while more severe constrictions and distal deformity can be treated with Z-plasty. The procedure is staged, with only half the circumference corrected at the first operation to prevent vascular compromise. Syndactyly/ acrosyndactyly are treated early to allow unimpeded growth of the fused digits. [20]

\section{Conclusions}

Constriction band syndrome is of unknown etiology and varied presentation and causes morbidity in the newborn. The prognosis is dependent on the severity of the associated defects. The syndrome and its complications can be easily diagnosed clinically and are amenable to corrective surgery with good results. Early intervention is needed for a successful outcome.

\section{References}

[1]. Pedersen TK, Thomsen SG. Spontaneous resolution of amniotic bands. Ultrasound Obstet Gynecol 2001;18:673-4

[2]. Kawamura K, Chung KC. Constriction band syndrome. Hand Clin. 2009 ;25(2):257-64

[3]. Walter JH Jr, Goss LR, Lazzara AT. Amniotic band syndrome. J Foot Ankle Surg. 1998 Jul-Aug; 37(4):325-33.

[4]. Streeter GL. Focal deficiencies in fetal tissues and their relation to intrauterine amputation. Contributions Embryol 1930;22:1-4

[5]. Torpin R. Amniochorionic mesoblastic fibrous strings and amniotic bands: Associated constricting fetal malformations or fetal death. Am J Obstet Gynaecol 1965; 91:65-75.

[6]. Kino Y. Clinical and experimental studies of the congenital constriction band syndrome, with an emphasis on its etiology. J B one Joint Surg Am 1995; 57: 636-43.

[7]. Patterson TJ. Congenital ring constrictions. Brit J Plast Surg 1961; 14:1-31.

[8]. Adu AJ, Annaw C. Congenital constriction ring syndrome of the limbs: a prospective study of 16 cases. Afr J Paed Surg 2008;5:79-83

[9]. Moran SL, Jensen M, Bravo C.Amniotic Band Syndrome of the Upper Extremity: Diagnosis and Management. J Am Acad Orthop Surg 2007; 15: (7) 397-407

[10]. Khan F, Shah SA, Naji Ullah Khan, Faheem Ullah. Pattern of constriction band syndrome $\cdot$ R M J 2010; 35(2):184-7. 
[11]. Cignini P, Giorlandino C, Padula F, Dugo N, Cafâ EV, SpataA Epidemiology and risk factors of amniotic band syndrome, or ADAM sequence J Prenat Med. 2012 ; 6(4): 59-63

[12]. Halder A. Amniotic band syndrome and/or limb body wall complex: split or lumpThe Application of Clinical Genetics 2010;3: 715

[13]. Osama T. Abu-Salah. Amniotic band syndrome; a case report Rawal Medical Journal 2011; 36:(2)

[14]. Poeuf B, Samson P, Maqalon G. Amniotic Band syndrome. Chir Main 2008;27 Suppl 1:136-47.

[15]. Gupta R, Malik F, Gupta R, Basit MA, Singh D. Congenital CBS. JK Science2008; 10:(2) 89-90 case report

[16]. Kamran A, Kahveci H, Oztur C. Case report Amniotic Band Sequence associated with Fronto-Ethmoidal Meningo-Encephalocele The New Journal of Medicine 2012;29(3):187-188

[17]. Pederside O, Omietimi JE, Adeyemi OO. Amniotic band syndrome: a report of two cases and review of the literature IOSRJDMS 2013;5:(3 ) PP 30-34

[18]. Mahony BS, Filly RA, Callen PW. The amniotic band syndrome: antenatal sonographic diagnosis and potential pitfalls. Am J Obstet Gynecol 1985; 152: 63.

[19]. Nardozza LM, Araujo E, Caetano AR, Moron AF. Prenatal Diagnosis of Amniotic Band Syndrome in the Third Trimester of Pregnancy using 3D Ultrasound. J Clin Imaging Sci 2012;2:22

[20]. Mahmood F, Tasneem S. Limb Threatening Constriction Ring Syndrome of Right Leg. J Neonat Surg 2012;1(3):47 